\title{
Long-Term Clinical Outcome and Survivorship Issues of High Grade Bone Sarcomas
}

\author{
Closset $C^{1^{*}}$, Ameye $L^{2}$, Gebhart, $M^{3}$, de Saint Aubain $N^{4}$, Beauvois $S^{5}$, Awada $A^{6}$, \\ Piccart $\mathbf{M}^{6}$, Gil, $\mathbf{T h}^{6}$
}

${ }^{1}$ Department of Internal medicine, Jules Bordet Institute (IJB), Brussels

${ }^{2}$ Department of Statistics, IJB, Brussels

${ }^{3}$ Department of Surgery, IJB

${ }^{4}$ Department of Anatomopathology, IJB

${ }^{5}$ Department of Radiotherapy, IJB

${ }^{6}$ Department of Medical oncology, IJB

*Corresponding author: Closset C, M.D, Deaprtment of Internal Medicine, Jules Bordet Institute (Bld de Waterloo 121, Rue de la Senne 57b, 1000 Bruxelles), Tel: 0474/89.18.68; E-mail: ceclosset@gmail.com

\begin{abstract}
:
We performed a retrospective review of 70 cases of high-grade bone sarcomas treated at the Institute Jules Bordet (IJB) between 2000 and 2008. Eighty nine percent of patients underwent surgery, 74\% chemotherapy, and 26\% radiotherapy with curative intent. The five-year overall survival rate was 60\% (osteosarcoma and Ewing's sarcoma: 55\%; chondrosarcoma: 85\%). The disease-free survival rates at five years were 64\% (osteosarcoma: 50\%; Ewing's sarcoma and chondrosarcoma: 78\%). One toxic death and one post-operative death occurred. We could identify the following 5-year side effect rates (without the unknowns): Infertility $92 \%$, cardiovascular disorders $18 \%$, hypercholesterolemia $41 \%$, hypertriglyceridemia $10 \%$, renal failure $11 \%$, functional disorders $50 \%$, osteoporosis $16 \%$, and chronic pain $26 \%$.

The clinical outcome of our patients compares favourably with the literature. Because the majority of patients are very young, quality of life issues is important for survivors. However, evaluating survivorship issues will remains inaccurate unless follow-up is standardized, with specials fields designated in the medical chart. This study emphasizes the need for rigorous systematization of the follow-up parameters used in medical charts in order to better identify survivors' needs.
\end{abstract}

Keywords: Bone Sarcoma; Quality of life; Treatment; Long-term side effects; Survival; Cancer centre experience

\section{Introduction}

Bone sarcomas are rare, representing $14 \%$ of all sarcomas and $0.2 \%$ of all cancer cases. They develop from within the bone and, more rarely, from the external bone tissue ${ }^{[1]}$. The three most frequent families of primary malignant bone tumours are osterosarcomas (35\%), chondrosarcomas (30\%), and Ewing's sarcomas $(15 \%)^{[2]}$.

Osteosarcoma is encountered in teenage patients and in patients over 65 years of age, while chondrosarcoma is diagnosed in patients over 20. Ewing's sarcoma appears mostly in young adolescents, and rarely after the age of 25 . Bone sarcomas occur mostly in the lower limbs and in the pelvic bones, but can affect any bone tissue ${ }^{[3]}$.

According to a European study published in 2013, the five-year survival rates are 54\% for osteosarcoma, $43 \%$ for Ewing's sarcoma, and $77 \%$ for chondrosarcoma ${ }^{[4]}$. Only $5 \%$ to $10 \%$ of chondrosarcomas are high grade, but these present high metastatic potential $(>60 \%)^{[5]}$. Due to their low sensitivity to radiotherapy and chemotherapy, free-margin surgery is essential.

The most important prognostic factors for bone sarco- mas at the time of diagnosis are the presence of metastases, the location and size of the tumour, the age of the patient, and blood LDH level. Response to chemotherapy also impacts outcome ${ }^{[6-8]}$. Approximately $20 \%$ of Ewing's sarcomas and osteosarcomas present macro-metastases at the time of diagnosis. However, most cases are thought to present micro-metastases, since in the absence of chemotherapy relapses are seen in $80 \%$ to $90 \%$ of patients. Relapses mainly occur during the first five years, and early relapsing cases have the worst prognosis ${ }^{[1-3]}$.

Received date: May 11, 2017

Accepted date: March 13, 2018

Published date: March 20, 2018

Citation: Closset, C., et al. Long-Term Clinical Outcome and Survivorship Issues of High Grade Bone Sarcomas. (2018) Int J Cancer Oncol 5(1): 26- 34.

Copyright: (C) 2018 Closset, C. This is an Open access article distributed under the terms of Creative Commons Attribution 4.0 International License. 
The initial treatment of every bone sarcoma case includes surgery, except for unresectable tumours ${ }^{[9]}$. Surgical progress has enabled amputations to decrease while keeping survival rate approximately constant ${ }^{[10,11]}$. Very few cases of osteosarcomas and chondrosarcomas are radiosensitive, unlike Ewing's sarcoma, for which radiotherapy is an effective treatment modality ${ }^{[9]}$.

Advances in chemotherapy in the 1970s significantly improved the survival rate of bone sarcomas. Without chemotherapy, the overall five-year survival rate for osteosarcomas and Ewing's sarcomas ranged between $16 \%$ and $30 \%$, while it increased to $55 \%$ to $70 \%$ with the addition of chemotherapy ${ }^{[12]}$. Response to chemotherapy depends on the histology. The initial pathological diagnosis is therefore essential in the choice of treatment. The most frequently used chemotherapy agents are doxorubicin, cisplatin, methotrexate, etoposide and ifosfamide, cyclophosphamide, vincristine and actinomycin ${ }^{[1,13]}$. Since chondrosarcomas are chemo-resistant, chemotherapy is not part of their management ${ }^{[9]}$.

Chemotherapy for bone tumors can produce serious adverse events, which include leukaemia's, metabolic disorders (e.g., osteoporosis ${ }^{[14]}$ and metabolic syndrome ${ }^{[15]}$ ), cardiac problems ${ }^{[16,17]}$, and renal-, gastrointestinal, pulmonary and gonadal toxicities $^{[18]}$; after radiotherapy, pulmonary fibrosis, gastrointestinal and urinary toxicities, secondary cancers, and interrupted bone growth are seen ${ }^{[16]}$; and, finally, surgery induces functional deficits and pain ${ }^{[19]}$. A minimum of ten years of follow-up is therefore recommended to detect relapses and any of these longterm side effects. Follow-up visits are frequent during the first years and more intermittent later on ${ }^{[1,9,20]}$. In this retrospective review of the medical records of patients with bone sarcomas treated at the Institute Jules Bordet (IJB), we analysed the treatment patterns, relapses and survival rates. We also analysed the long-term side effects, which are integral to survivorship. Bone sarcomas being "rare" cancers, we hope that this work will contribute to lessening the gaps in the medical literature, and to giving direction for the future.

\section{Material and Methods}

\section{Objectives}

Our first objective was to review the treatments, relapse rates, and survival rates of patients with high-grade bone sarcomas treated at the IJB. Our second objective was to review the acute and long term adverse effects and the psychosocial state of survivors.

\section{Data collection}

The period chosen for this review (2000 to 2008) allowed for a minimum follow-up of five years. All high-grade chondrosarcomas (grades 2 to 3 ) as well as all osteosarcomas and Ewing's sarcomas were included, regardless of age and sex. We also included a few rare bone cancers, such as one highgrade undifferentiated pleomorphic sarcoma and one leiomyosarcoma. These and the external bone-tissue Ewing's sarcomas and osteosarcomas were also included because they had been treated similarly. All cases included in this study benefited from at least one of the main treatment modalities (chemotherapy, surgery, radiotherapy or palliative care) at IJB.
All data have been gathered from IJB files, and from those of HUDERF (Hôpital Universitaire des Enfants Reine Fabiola) when patients who were minors were partially treated there. The data were collected into a case report form (CRF) prepared according to the review of the literature and to the objectives above. The database was built using Microsoft Access 2007 software.

\section{Data analysis}

As there was no formal hypothesis, the statistical analyses were mainly descriptive. Continuous variables were presented as mean \pm standard deviation and median ( $\min -\max$ ). Categorical variables were presented as number and percentage. To compare differences in categorical variables between different types of sarcomas, the Fisher Exact test was used. To compare differences in continuous variables between different types of sarcomas, the t-test was used. Overall survival (OS) was defined as the time from the date of diagnosis to the date of death. Patients who were still alive were censored at the date of the last follow-up. Disease-free survival (DFS) was assessed in patients with stage I, II and III patient'sdiseases, and was defined as the time from the date of diagnosis to the date of relapse or death, whichever occurred first. Survival was analysed with Kaplan-Meier curves and log rank test. All statistical analyses were performed with SAS 9.4, SAS Institute Inc., Cary, NC, USA.

\section{Results (Percentages are computed excluding unknowns)}

\section{General characteristics and demographics}

From 2000 till 2008, 70 patients started treatment (complete or partial) at IJB for a high-grade bone sarcoma. Table1 summarizes the demographic data of the patients. The difference in median age between the chondrosarcoma group (59) and the other bone sarcomas is significant $(\mathrm{p}<0.001)$, while there is no significant difference between the two sexes $(p=0.85)$. S

Table 1: The demographic data of the 70 patients. Others $=$ leiomyosarcoma and synoviosarcoma of the bone. HGUPS = high grade undifferentiated pleomorphic sarcoma.

\begin{tabular}{|c|c|c|c|c|c|c|}
\hline & Total & $\begin{array}{l}\text { Osteo- } \\
\text { sarco- } \\
\text { mas }\end{array}$ & $\begin{array}{l}\text { Ewing's } \\
\text { Sarco- } \\
\text { mas }\end{array}$ & $\begin{array}{l}\text { Chon- } \\
\text { drosar- } \\
\text { comas }\end{array}$ & HGUPS & $\begin{array}{l}\text { Oth- } \\
\text { ers }\end{array}$ \\
\hline \multicolumn{7}{|c|}{ Age at diagnosis } \\
\hline N (\%) & 70 & $29(41)$ & $23(33)$ & $14(20)$ & $2(3)$ & $2(3)$ \\
\hline Mean \pm SD & $34 \pm 22$ & $34 \pm 24$ & $22 \pm 12$ & $56 \pm 14$ & & \\
\hline $\begin{array}{l}\text { Median } \\
\text { (min-max) }\end{array}$ & $\begin{array}{l}25 \\
(4-82)\end{array}$ & $\begin{array}{l}21 \\
(5-82)\end{array}$ & $\begin{array}{l}18 \\
(4-60)\end{array}$ & \begin{tabular}{|l}
59 \\
$(32-77)$ \\
\end{tabular} & $(39-44)$ & $\begin{array}{l}(19- \\
44)\end{array}$ \\
\hline \multicolumn{7}{|l|}{ Gender } \\
\hline Women & $28(40 \%)$ & $13(45 \%)$ & $9(39 \%)$ & $5(36 \%)$ & - & 1 \\
\hline Men & $42(60 \%)$ & $16(55 \%)$ & $14(61 \%)$ & $9(64 \%)$ & 2 & 1 \\
\hline
\end{tabular}

The primary location of bone sarcomas is preferentially the femur $(25 / 70 ; 36 \%)$, especially for the osteosarcomas $(15 / 29 ; 52 \%)$; they were also found in the distal lower limbs $(13 / 70 ; 19 \%)$ and the pelvis $(11 / 70 ; 16 \%)$. In addition, in $(8 / 70)$ $11 \%$ of cases the primary location of the bone sarcoma was in external bone tissue (Table 2). In long bones, the shaft is reached in $75 \%$ of all cases. 
Citation: Closset, C., et al. Long-Term Clinical Outcome and Survivorship Issues of High Grade Bone Sarcomas. (2018) Int J Cancer Oncol 5(1): 26- 34.

Table 2: Primary location by type of sarcoma. Others = jaw and rachis

\begin{tabular}{|l|l|l|l|l|l|l|l|}
\hline $\begin{array}{l}\text { Fre- } \\
\text { quencies } \\
\text { n (\%) }\end{array}$ & $\begin{array}{l}\text { Fe- } \\
\text { mur }\end{array}$ & $\begin{array}{l}\text { Tibia/ } \\
\text { fibula/ } \\
\text { foot }\end{array}$ & Pelvis & $\begin{array}{l}\text { Up- } \\
\text { per } \\
\text { limb }\end{array}$ & Others & $\begin{array}{l}\text { Extra } \\
\text { osse- } \\
\text { ous }\end{array}$ & $\begin{array}{l}\text { To- } \\
\text { tal }\end{array}$ \\
\hline $\begin{array}{l}\text { Osteosar- } \\
\text { comas }\end{array}$ & $15(52)$ & $4(14)$ & $1(3)$ & $1(3)$ & $3(10)$ & $5(17)$ & 29 \\
\hline $\begin{array}{l}\text { Ewing's } \\
\text { sarcomas }\end{array}$ & $5(22)$ & $6(26)$ & $6(26)$ & 0 & $3(13)$ & $3(13)$ & 23 \\
\hline $\begin{array}{l}\text { Chondro- } \\
\text { sarcomas }\end{array}$ & $4(29)$ & $2(14)$ & $4(29)$ & $2(14)$ & $2(14)$ & 0 & 14 \\
\hline HGUPS & $1(50)$ & 0 & 0 & 0 & $1(50)$ & 0 & 2 \\
\hline Others & 0 & $1(50)$ & 0 & 0 & $1(50)$ & 0 & 2 \\
\hline Total & $25(36)$ & $13(19)$ & $11(16)$ & $3(4)$ & $10(14)$ & $8(11)$ & 70 \\
\hline
\end{tabular}

The medical charts were found to lack previous lifestyle information. Cryoconservation data were gathered for 48 patients. Thirteen of them underwent cryoconservation for fertility purposes before the beginning of chemotherapy. Their average age was 20 . The 35 patients who did not undergo cryoconservation were on average 51 years old. This age difference is statistically significant $(\mathrm{p}<0.001)$. None of the patients had children during their follow-up, and cryoconservation has not been used so far.

\section{Diagnosis}

The most frequent symptoms at the time of diagnosis were pain $(57 / 70,81 \%)$ and swelling $(41 / 70,59 \%)$, while systemic symptoms like weight loss, anaemia, fever, fatigue were less present $(<10 \%)$. Performance status (PS using the WHO scale) evaluation was generally very good at the time of diagnosis: $70 \%(49 / 70)$ of patients had a PS of $0 ; 20 \%(14 / 70)$ a PS of 1 ; and less than $10 \%(<7 / 70)$ a PS of 4 .

Diagnostic open biopsies were performed in 95\% $(66 / 70)$ of cases. The diagnosis and the local assessment were most often performed using standard radiology $(74 \%, 52 / 70)$ and MRI $(91 \%, 64 / 70)$. On the other hand, the general work-up most often consisted in a chest scan $(89 \%, 62 / 70)$, abdominal imaging/evaluation $(72 \%, 50 / 70)$, and a bone scan $(80 \%, 56 / 70)$. PET scans were used in $31 \%$ (22/70) of cases as part of the initial assessment.

\section{Treatment}

Surgery: Sixty-three of the 70 patients (89\%) underwent surgical removal of their primary tumour. Seventeen patients also underwent surgery for a local relapse or for distant metastases. The surgical margins obtained during the first surgery of the primary tumour were free in $80 \%$ of the cases involving the lower limbs, in $55 \%$ of cases involving the pelvis, and in more than $65 \%$ of cases involving external bone tissues. By contrast, only $21 \%$ of the surgical procedures in other locations resulted in free margins (Figures 1 and 2).

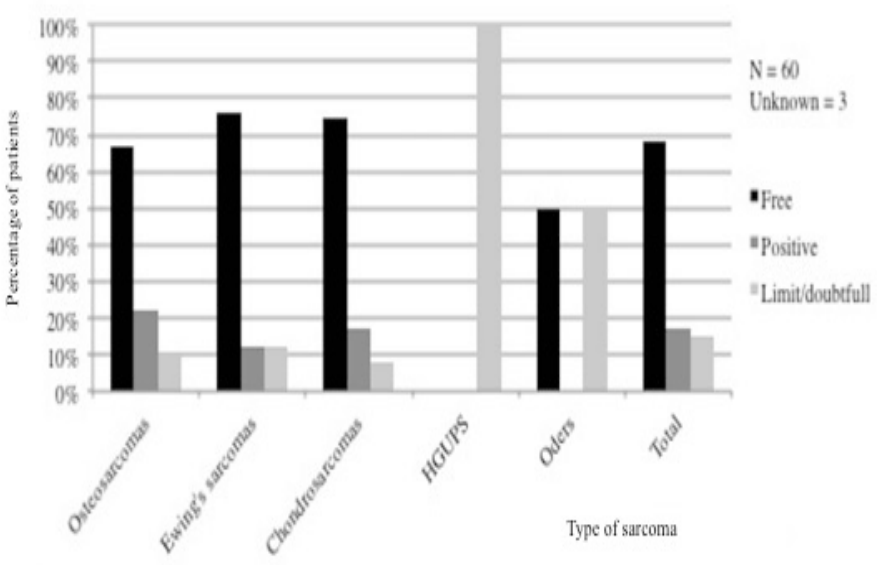

Figure 1: Surgical margins by type of sarcoma.

Surgery achieved tumour-free margins more frequently with tumours of the limbs than of the pelvis, but no significant difference was found $(\mathrm{p}=0.2)$.

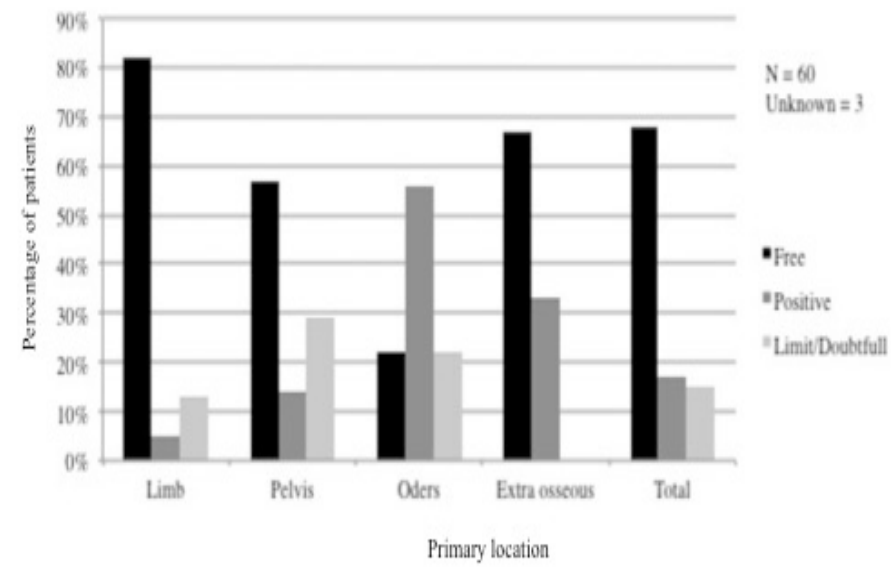

Figure 2: Surgical margins by primary location.

Among the 84 surgeries, there were 8 amputations ( $10 \%$ of patients) and $47(56 \%)$ cases of resection followed by a reconstruction.

Chemotherapy: Among the 70 patients, 52 (74\%) underwent chemotherapy. Three of them were treated in the neoadjuvant setting, 13 received adjuvant therapy, 28 received both, and 8 had palliative chemotherapy. All Ewing's sarcomas, $82 \%$ of osteosarcomas, and only $14 \%$ of the chondrosarcomas were treated with chemotherapy. Thirty-five (50\%) patients were treated with curative chemotherapy, 15 patients received initial chemotherapy with curative intent and palliative chemotherapy later, and 2 patients $(3 \%)$ received only palliative chemotherapy. Thirty-nine percent of osteosarcomas and $61.5 \%$ of Ewing's sarcomas responded well to neoadjuvant chemotherapy ( $>90 \%$ of necrosis).

Radiotherapy: Among the 70 patients, 32 underwent radiotherapy: 19 on the primary tumour site, 5 on the lungs, and 1 on a bone metastasis. Eighteen patients received radiotherapy as part of their primary treatment: 1 was intraoperative, 11 postoperative, and 6 were exclusively treated with radiotherapy. Sixteen (69\%) of the 23 patients with Ewing's sarcoma had radiotherapy and, among them, 7 patients $(30 \%)$ had only curative radiother- 
apy. The others received exclusively palliative radiotherapy or palliative after curative radiotherapy. Ten patients (34\%) with osteosarcomas and $4(28 \%)$ with chondrosarcomas had radiotherapy, but few of them ( 5 and 1 patients respectively) received only curative radiotherapy.

Relapses: Among the 50 patients experiencing complete remission, 23 (46\%) relapsed as follows: $10(43.5 \%)$ recurred locoregionally, $10(43.5 \%)$ in the lungs, and $3(13 \%)$ in bone tissues or lymph nodes. On average, relapses occurred one year and 8 months after diagnosis, with a median of 1.5 years. The latest relapse occurred 4.5 years after diagnosis. There is no survival difference following early $(<1.5$ years $)$ or late $(>1.5$ years $)$ relapses in our series $(\mathrm{p}=0.7)$.

Relapses were documented by MRI (75\%), CT scan (57\%) and PET-CT (35\%). Clinical signs were present in $68 \%$ of cases. There was no statistically significant difference in survival rates between asymptomatic (relapses identified only by imaging) and symptomatic ones $(p=0.98)$. (Figure 3 ). Figure 4 demonstrates a trend for better DFS in patients who benefited from free-margin surgery $(\mathrm{p}=0.16)$.

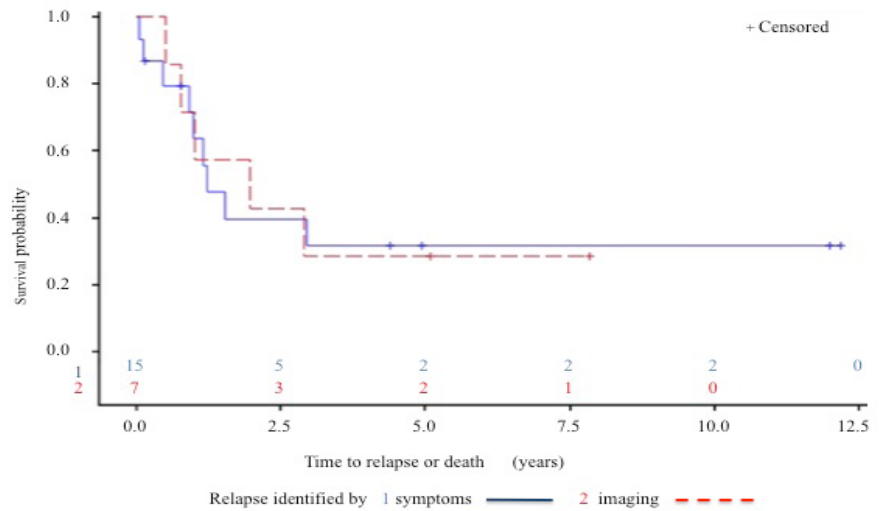

Figure 3: Survival rates between relapses identified by symptoms (1) and by imaging (2).

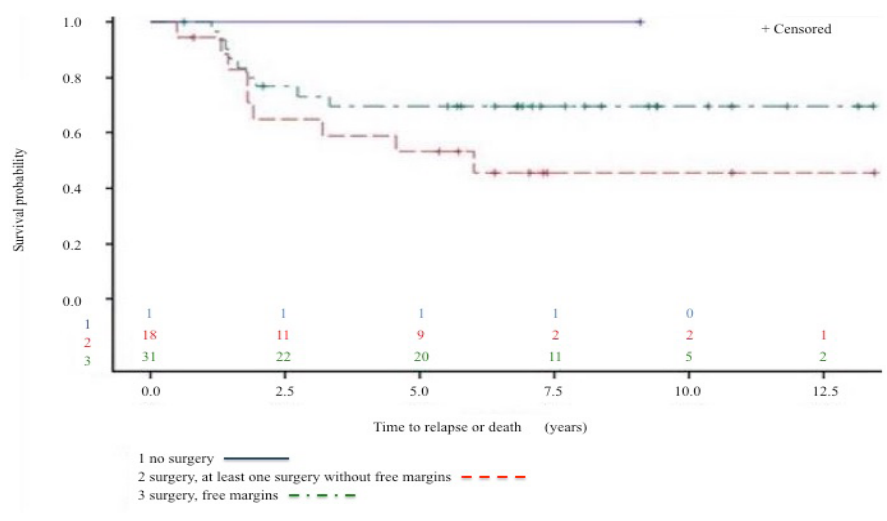

Figure 4: DFS by margin surgery.

Relapses mostly occurred during the second year, and no relapse was observed beyond five years. Patients with progression died rather rapidly. The majority of deaths occurred in the first three years after diagnosis.
Survival: The 5-year DFS rate (Figure 5 to 7 ) is $64 \%$ and the 5 -year OS rate is $60 \%$ (Figure 8 to 10 ). There is no significant difference in OS $(\mathrm{p}=0.15)$ for chondrosarcomas compared to the other histologies (Figure 9), nor in DFS $(\mathrm{P}=0.06)$ for osteosarcomas compared to Ewing's sarcomas and chondrosarcomas (Figure 6). As expected, there is a significant difference in OS and DFS rates depending on disease stage $(\mathrm{p}<0.002$ and $\mathrm{p}=$ 0.04) (Figure 7 and 10).

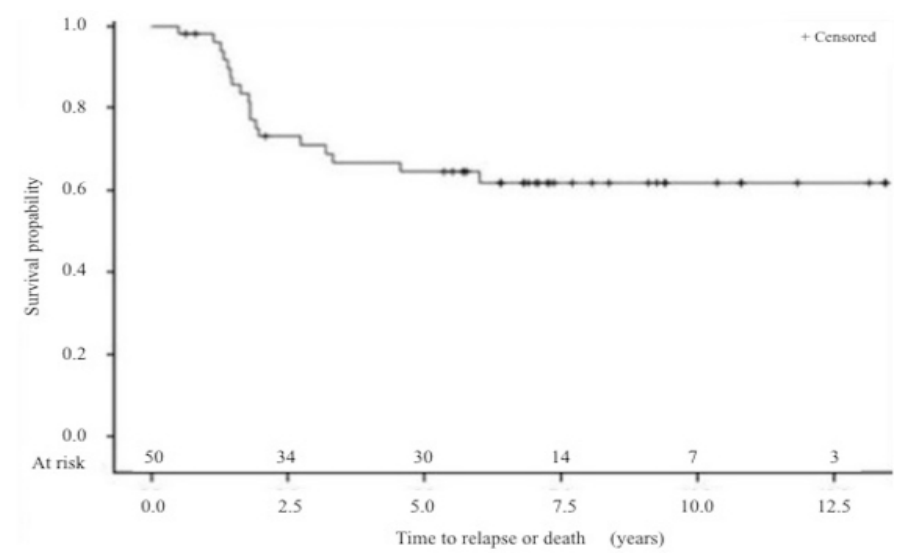

Figure 5: Disease free survival (DFS) (Stage IV excluded) 5 years DFS rate was $64 \%(95 \% \mathrm{CI}, 49 \%$ to $76 \%)$.

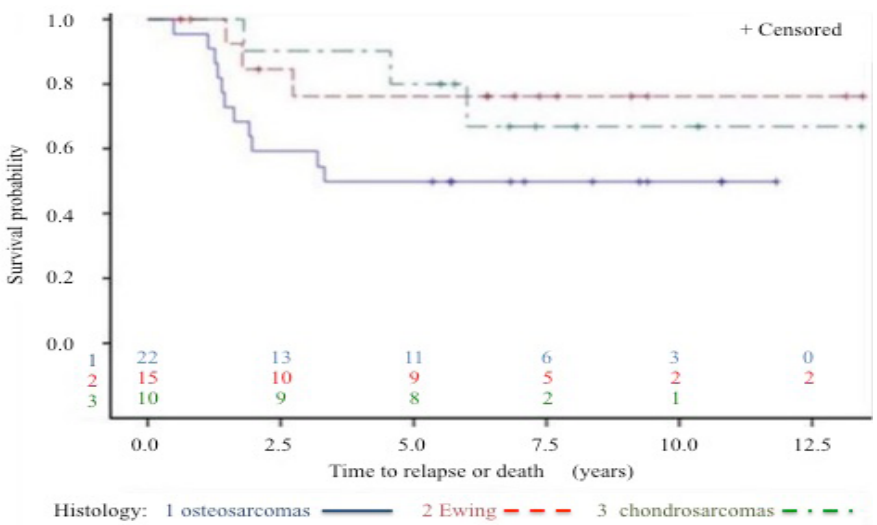

Figure 6: DFS by type of sarcoma. Osteosarcomas versus Ewing's \& chondrosarcomas: p 0.06. 5-years DFS rate in osteosarcomas: $50 \%$ (95\% CI, $28 \%$ to $68 \%$ ). 5 -years DFS rate in Ewing \& chondrosarcomas: $78 \%$ (95\% CI, $55 \%$ to $90 \%)$.

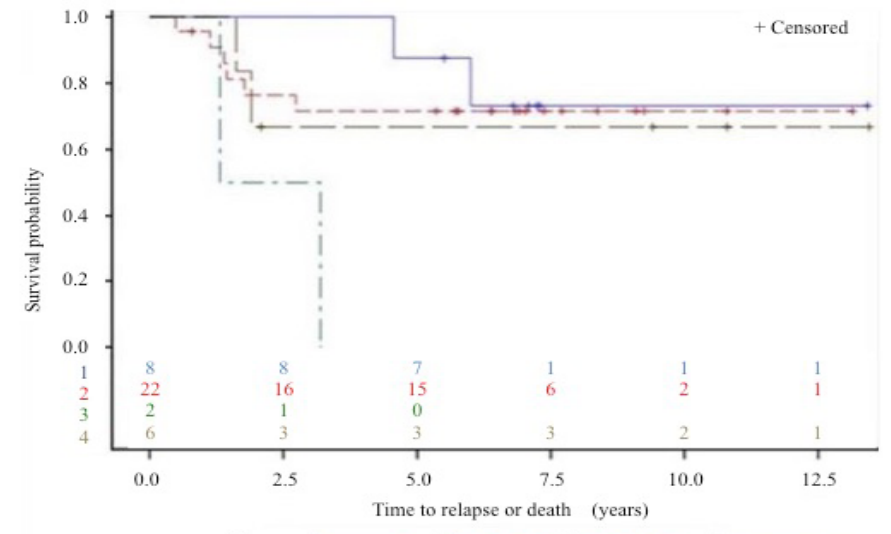

Figure 7: DFS by stage at diagnosis. 


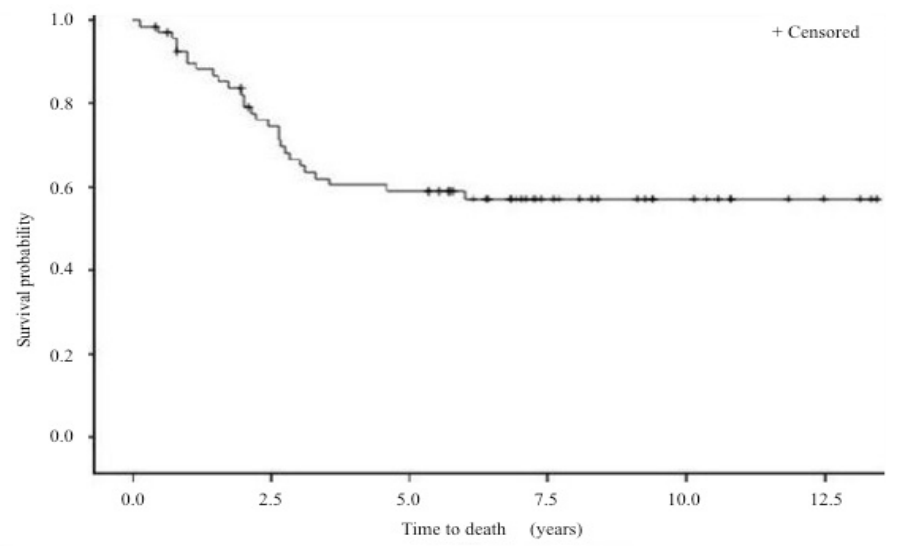

Figure 8: Overall survival (OS) rate.

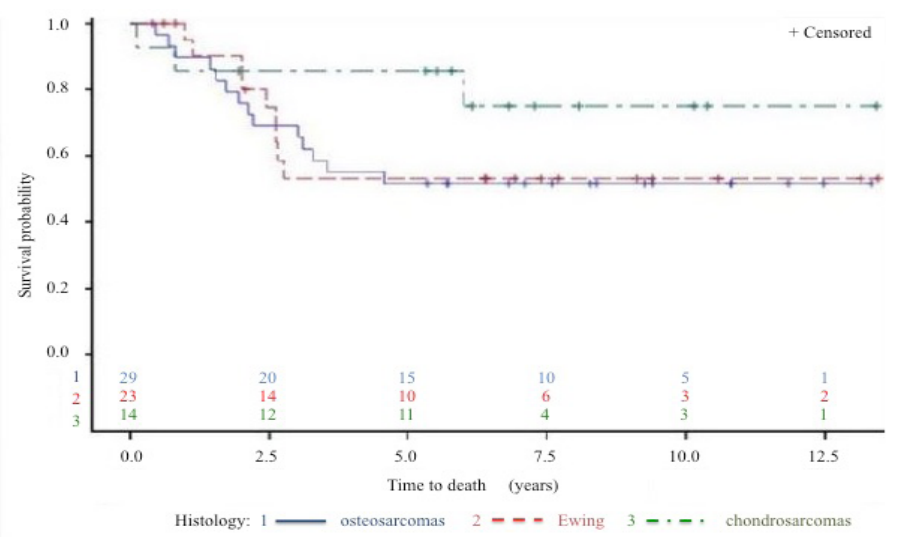

Figure 9: OS by type of sarcoma.

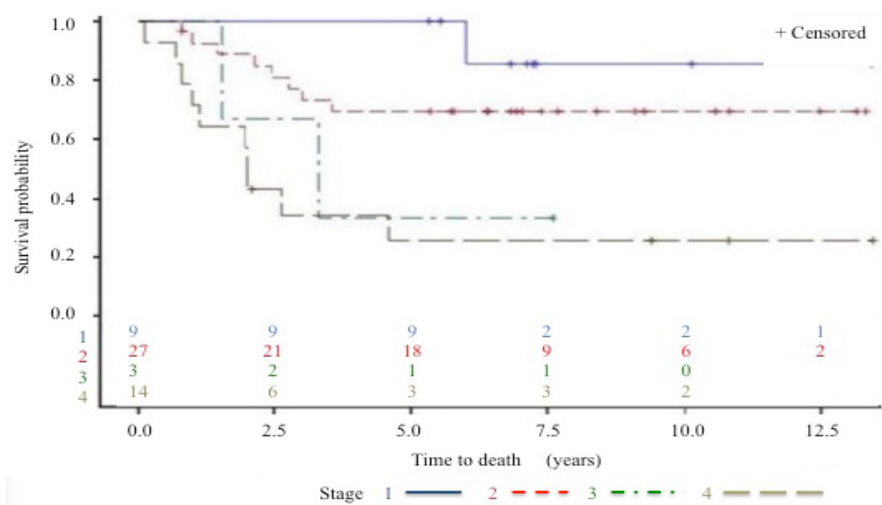

Figure 10: OS by stage at diagnosis.

\section{Adverse effects}

Long term adverse effects: At 5 years of follow-up, 12 patients were known to be infertile and one was fertile but he did not have children. For the remaining 21 patients who were alive, the information is lacking, and 36 patients died or were lost to follow-up. Information about sexual dysfunction could not be found in the medical charts.

Six patients suffered from a cardiovascular disorder, but the latter existed before the disease. Nine patients showed hypercholesterolemia, of which 3 had this abnormal laboratory value before starting treatment. Two patients had hypertriglyceridemia and 5 patients a renal failure during the year-long observation period. Functional disorders (compared to before the diagnosis) were present in 16 patients; osteoporosis or fracture was found in 5 patients; and chronic pain was reported by 8 patients.
Among the 51 patients with primary tumours that could affect the ability to walk, at 5 years of follow-up, 17 patients had a normal walking, 7 patients had a lameness, 2 walked with crutches or a cane, and nobody was wheelchair-bound.

Table 3 displays long term adverse effects recorded during a period of 5 to 13 years after diagnosis. More details on these adverse effects are provided in Figures 11 to 19.

Table $3 \mathrm{a}$ and $3 \mathrm{~b}$ : Chronic adverse effects according to each year of follow-up. $1^{\text {st }}$ year: 60 patients alive and not lost to follow-up. $2^{\text {nd }}$ year: 53 patients alive and not lost to follow-up. $3^{\text {rd }}$ year: 41 patients alive and not lost to follow-up. $4^{\text {th }}$ year: 37 patients alive and not lost to follow-up. $5^{\text {th }}$ year: 34 alive and not lost to follow-up. $6^{\text {th }}$ to $13^{\text {th }}$ year: 29 patients alive and not lost to follow-up.

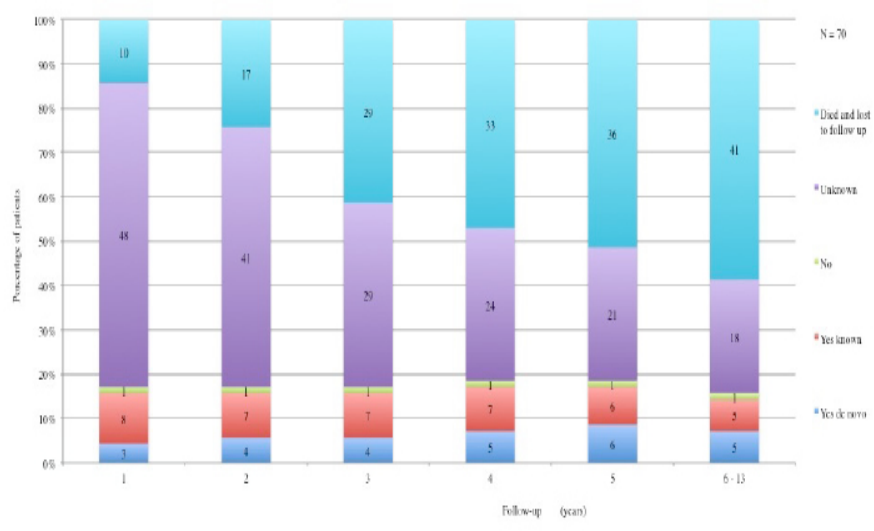

Figure 11: Long term adverse effects: Infertility. Identified by semen analysis for men and by hormone levels for women

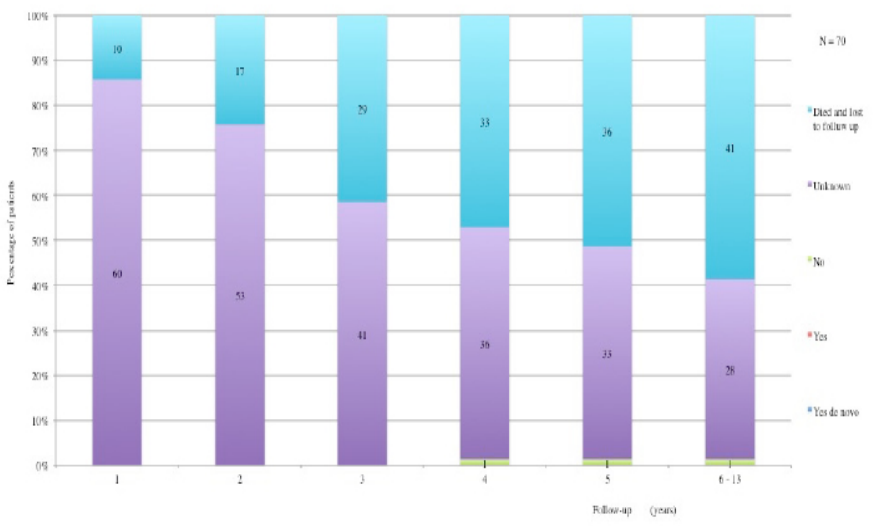

Figure 12: Long term adverse effects: Sexual dysfunctions (anamnesis)

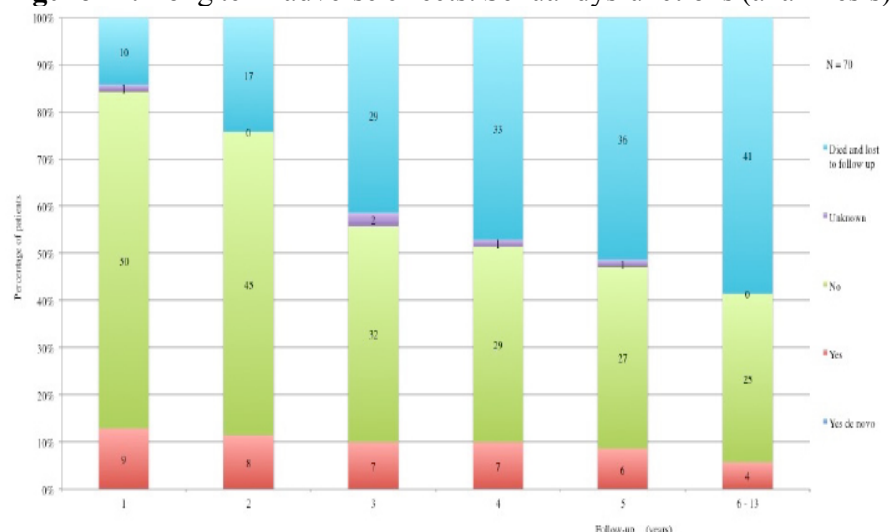

Figure 13: Long term adverse effects: Cardiovascular disorders (CV) (HTA, cardiomyopathies, strokes). Yes: All patients already had a CV before the disease exceptpatient in the fourth year of follow-up. 


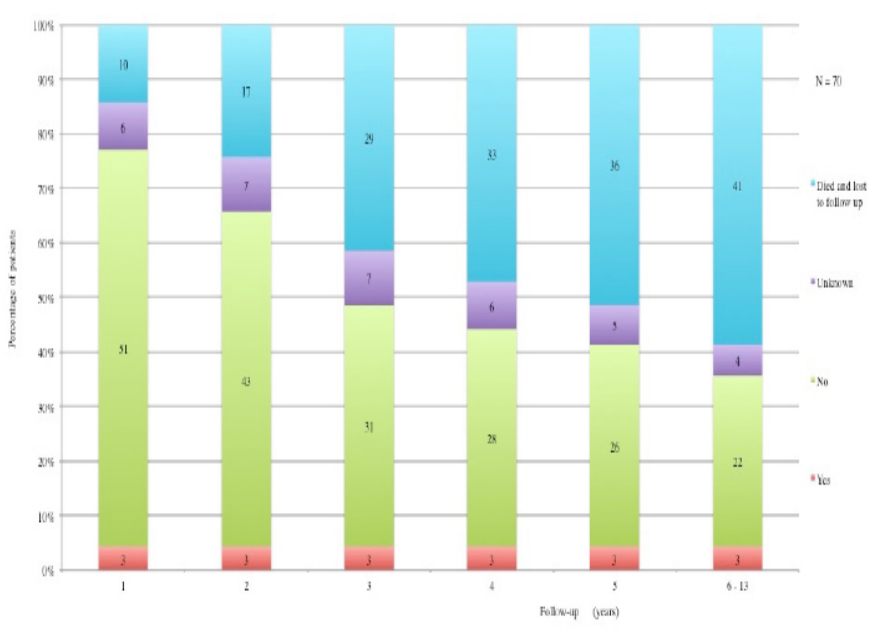

Figure 14: Long term adverse effects: Renal failure. Creatinine dosage $>1(\mathrm{~F})$ and $>1,2(\mathrm{M}) \mathrm{mg} / \mathrm{dl}$. Mean: $1,35 \mathrm{mg} / \mathrm{dl}$ (minimum $1,1 \mathrm{mg} / \mathrm{dl}$; maximum $1,7 \mathrm{mg} / \mathrm{dl})$.

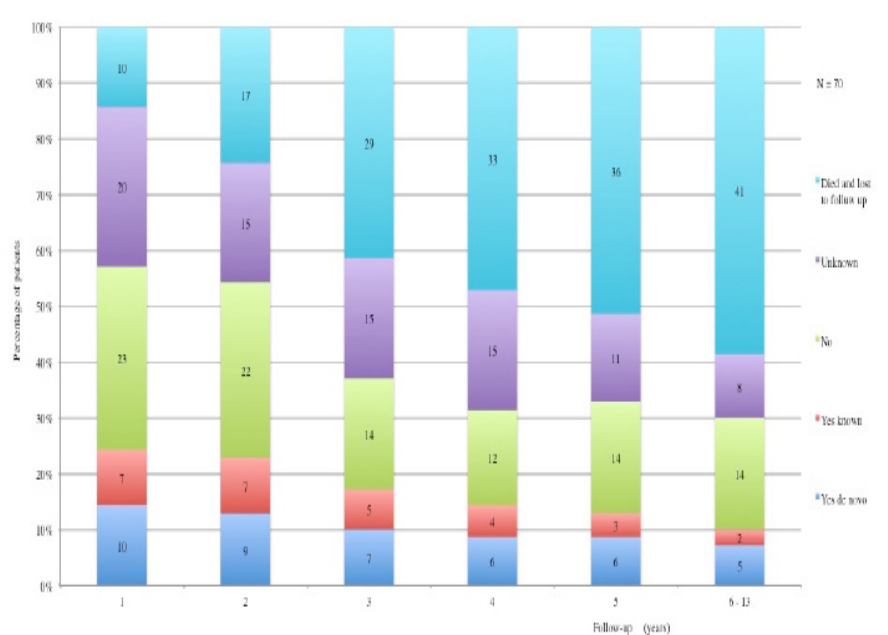

Figure 15: Long term adverse effects: Hypercholesterolemia. Total cholesterol $>190 \mathrm{mg} / \mathrm{dl}$.

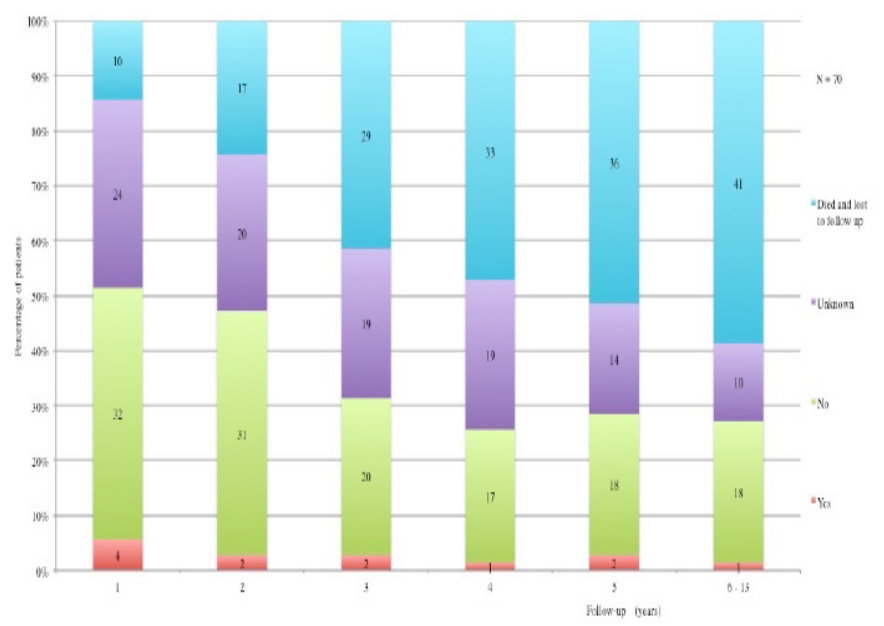

Figure 16: Long term adverse effects: Hypertriglyceridemia. Triglyceride $>150 \mathrm{mg} / \mathrm{dl}$.

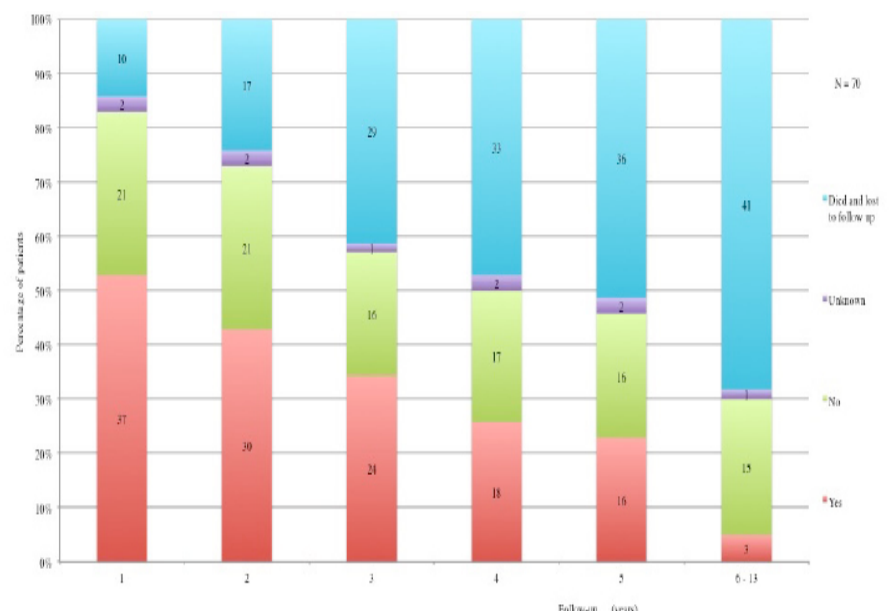

Figure 17: Long term adverse effects: Functional disorders compared to initial physical status before de disease.

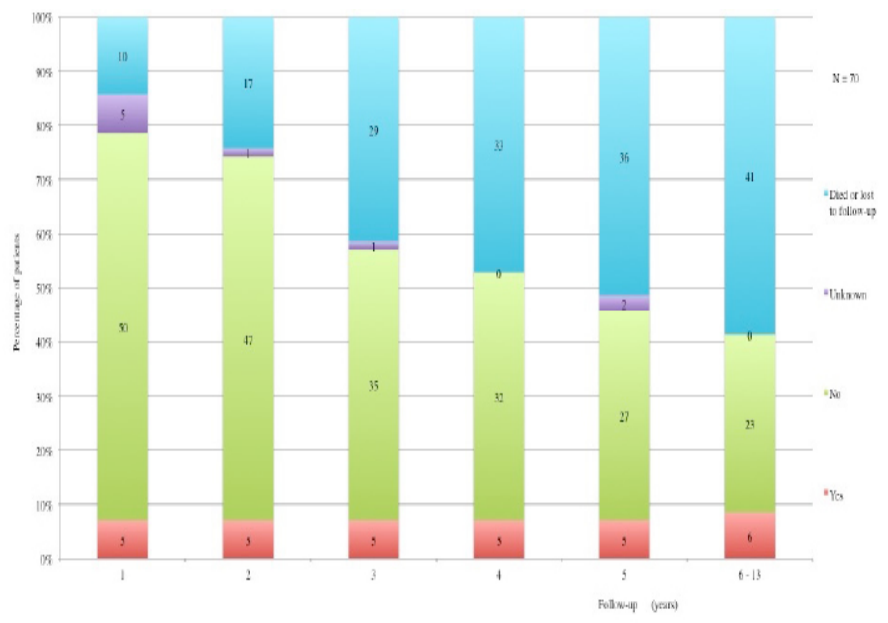

Figure 18: Long term adverse effects: Osteoporosis and fracture.

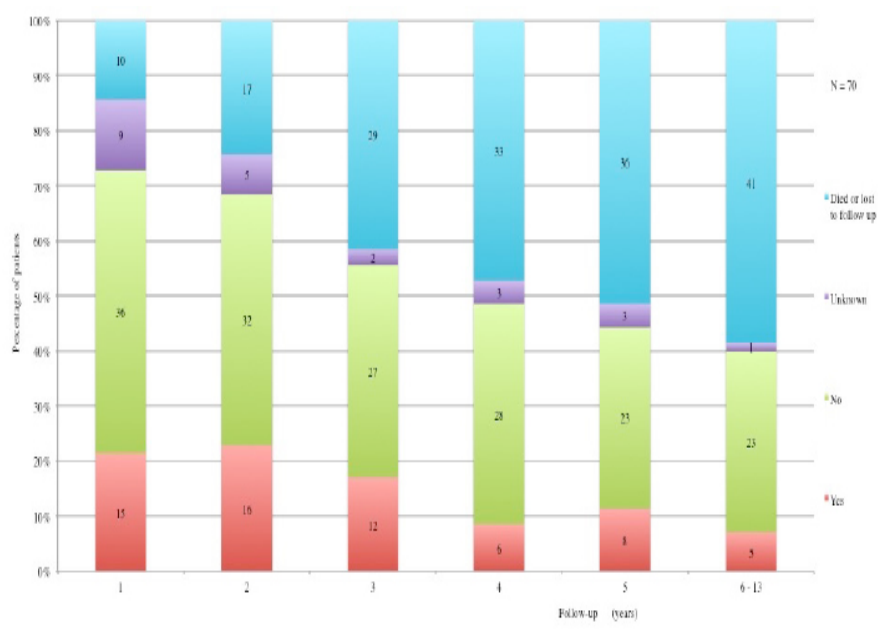

Figure 19: Long term adverse effects: Pain after treatment. 
Citation: Closset, C., et al. Long-Term Clinical Outcome and Survivorship Issues of High Grade Bone Sarcomas. (2018) Int J Cancer Oncol 5(1): 26- 34 .

Table IIIa and Table IIIb: Chronic adverse effects according to each year of follow-up.

$1^{\text {st }}$ year: 60 patients alive and not lost to follow-up. $2^{\text {nd }}$ year: 53 patients alive and not lost to follow-up. $3^{\text {rd }}$ year: 41 patients alive and not lost to follow-up. $4^{\text {th }}$ year: 37 patients alive and not lost to follow-up. $5^{\text {th }}$ year: 34 alive and not lost to follow-up. $6^{\text {th }}$ to $13^{\text {th }}$ year: 29 patients alive and not lost to follow-up.

\begin{tabular}{|c|c|c|c|c|c|c|c|c|c|}
\hline \multirow{2}{*}{$\begin{array}{l}\text { IIIa } \\
\text { n (\%) }\end{array}$} & \multicolumn{3}{|c|}{$1^{\text {st }}$ year } & \multicolumn{3}{|c|}{$2^{\text {nd }}$ year } & \multicolumn{3}{|c|}{$3^{\text {rd }}$ year } \\
\hline & Yes & No & Unknown & Yes & No & Unknown & Yes & No & Unknown \\
\hline Infertility & $11(91)$ & 1 & 48 & $11(91)$ & 1 & 41 & $11(91)$ & 1 & 29 \\
\hline Sexual dysfunction & 0 & 0 & 60 & 0 & 0 & 53 & 0 & 0 & 41 \\
\hline Early menopause & $9(16)$ & 46 & 5 & $8(16)$ & 41 & 4 & $7(18)$ & 32 & 2 \\
\hline Hormone replacement treatment & $6(8)$ & 53 & 1 & $4(8)$ & 48 & 1 & $4(10)$ & 37 & 0 \\
\hline Renal failure & $3(5)$ & 51 & 6 & $3(6)$ & 43 & 7 & $3(9)$ & 31 & 7 \\
\hline Hyper triglyceridemia & $4(11)$ & 32 & 24 & $2(6)$ & 30 & 20 & $2(9)$ & 20 & 19 \\
\hline Hypercholesterolemia & $17(42)$ & 23 & 20 & $16(42)$ & 22 & 15 & $12(46)$ & 14 & 15 \\
\hline Cardiovascular disorders & $9(15)$ & 50 & 1 & $8(15)$ & 45 & 0 & $7(18)$ & 32 & 2 \\
\hline Intestinal toxicity & $4(7)$ & 55 & 1 & $4(7)$ & 49 & 0 & $2(5)$ & 38 & 1 \\
\hline Lung fibrosis & 0 & 58 & 2 & 0 & 52 & 1 & 0 & 40 & 1 \\
\hline Voiding dysfunction & $5(8)$ & 54 & 1 & $4(7)$ & 49 & 0 & $1(2)$ & 39 & 1 \\
\hline Edema of the affected limb & $2(4)$ & 55 & 3 & $3(6)$ & 49 & 1 & $2(5)$ & 39 & 0 \\
\hline Limb distortion & $3(5)$ & 55 & 2 & $4(7)$ & 49 & 0 & $5(12)$ & 36 & 0 \\
\hline Functional disorders & $37(64)$ & 21 & 2 & $30(59)$ & 21 & 2 & $24(60)$ & 16 & 1 \\
\hline Osteoporosis/fracture & $5(9)$ & 50 & 5 & $5(10)$ & 50 & 1 & $5(12)$ & 35 & 1 \\
\hline Pain & $15(29)$ & 36 & 9 & $16(33)$ & 32 & 5 & $12(31)$ & 27 & 2 \\
\hline Sensory neuropathy & $4(7)$ & 52 & 4 & $1(2)$ & 49 & 3 & $3(8)$ & 37 & 1 \\
\hline Necrosis of femoral head & 0 & 59 & 1 & 0 & 53 & 0 & 0 & 41 & 0 \\
\hline Fatigue & $16(43)$ & 21 & 23 & $12(38)$ & 20 & 21 & $5(19)$ & 21 & 15 \\
\hline Distress & $15(45)$ & 18 & 27 & $11(37)$ & 19 & 23 & $8(29)$ & 20 & 13 \\
\hline Second cancer & 0 & 59 & 1 & 0 & 53 & 0 & 0 & 41 & 0 \\
\hline
\end{tabular}

Table IIIb: Chronic adverse effects according to each year of follow-up.

\begin{tabular}{|c|c|c|c|c|c|c|c|c|c|}
\hline \multirow{2}{*}{$\begin{array}{l}\text { IIIb } \\
\text { n (\%) }\end{array}$} & \multicolumn{3}{|c|}{$4^{\text {th }}$ year } & \multicolumn{3}{|c|}{$5^{\text {th }}$ year } & \multicolumn{3}{|c|}{$6^{\text {th }}$ to $13^{\text {th }}$ years } \\
\hline & Yes & No & Unknown & Yes & No & Unknown & Yes & No & Unknown \\
\hline Infertility & $12(92)$ & 1 & 24 & $12(92)$ & 1 & 21 & $10(91)$ & 1 & 18 \\
\hline Sexual dysfunction & $0(0)$ & 1 & 36 & $0(0)$ & 1 & 33 & $0(0)$ & 1 & 28 \\
\hline Early menopause & $8(22)$ & 29 & 0 & $7(21)$ & 26 & 1 & $7(24)$ & 22 & 0 \\
\hline Hormone replacement treatment & $5(13)$ & 32 & 0 & $6(27)$ & 16 & 1 & $5(17)$ & 24 & 0 \\
\hline Renal failure & $3(10)$ & 28 & 6 & $3(11)$ & 25 & 5 & $3(12)$ & 22 & 4 \\
\hline Hyper triglyceridemia & $1(5)$ & 17 & 19 & $2(10)$ & 17 & 14 & $1(5)$ & 18 & 10 \\
\hline Hypercholesterolemia & $10(45)$ & 12 & 15 & $9(41)$ & 13 & 11 & $7(33)$ & 14 & 8 \\
\hline Cardiovascular disorders & $7(19)$ & 29 & 1 & $6(18)$ & 27 & 1 & $4(14)$ & 25 & 0 \\
\hline Intestinal toxicity & $2(5)$ & 34 & 1 & $2(6)$ & 31 & 1 & $3(10)$ & 26 & 0 \\
\hline Lung fibrosis & $0(0)$ & 36 & 1 & $0(0)$ & 33 & 1 & $0(0)$ & 29 & 0 \\
\hline Voiding dysfunction & $1(3)$ & 35 & 1 & $1(3)$ & 32 & 1 & $1(3)$ & 28 & 0 \\
\hline Edema of the affected limb & $1(3)$ & 36 & 0 & $0(0)$ & 33 & 1 & $1(7)$ & 26 & 2 \\
\hline Limb distortion & $6(16)$ & 31 & 0 & $4(12)$ & 28 & 2 & $5(18)$ & 23 & 1 \\
\hline Functional disorders & $18(51)$ & 10 & 2 & $16(50)$ & 16 & 2 & $13(46)$ & 15 & 1 \\
\hline Osteoporosis/fracture & $19(65)$ & 10 & 0 & $5(16)$ & 25 & 2 & $6(21)$ & 23 & 0 \\
\hline Pain & $6(21)$ & 23 & 3 & $8(26)$ & 23 & 3 & $5(18)$ & 23 & 1 \\
\hline Sensory neuropathy & $4(14)$ & 25 & 0 & $3(9)$ & 29 & 2 & $2(7)$ & 27 & 0 \\
\hline Necrosis of femoral head & $0(0)$ & 0 & 0 & $0(0)$ & 33 & 1 & $0(0)$ & 39 & 0 \\
\hline Fatigue & $5(14)$ & 32 & 13 & $2(10)$ & 18 & 14 & $1(5)$ & 19 & 9 \\
\hline Distress & $6(18)$ & 28 & 12 & $3(15)$ & 17 & 14 & $2(10)$ & 18 & 9 \\
\hline Second cancer & 0 & 37 & 0 & $0(0)$ & 33 & 1 & $1(3)$ & 28 & 0 \\
\hline
\end{tabular}




\section{Discussion}

The results of this retrospective review of 70 cases of high-grade bone cancers treated at IJB between 2000 and 2008 are similar to what can be found in the literature. Our work was carried out with emphasis on rigorous data collection. Homogeneity in data collection was ensured by defining precise criteria from the start, with the aim to reduce subjectivity bias. These criteria were incorporated into case report forms. Most published bone sarcoma studies focus on a specific aspect, such as survival rates or adverse side effects from therapies. Our results are discussed with respect to these studies and to the current treatment guidelines.

At IJB we followed European protocols and guidelines. The first point to note is the low amputation rate $(10 \%)$, which denotes important progress and allows for considerable improvement of the quality of life of survivors. The second point to highlight is the apparent increase in DFS after free-margin surgery ${ }^{[21]}$. However, a patient or tumour selection bias could be at play here: smaller tumours are more easily operable with free margins and show a better prognosis.

The five-year survival rates of our patients are similar to those found in the literature ${ }^{[4]}$. One exception is the survival rate of high-grade chondrosarcomas, which reached $70 \%$ in our series, while it rarely exceeds $60 \%$ in the literature. This could be due to the use of different definitions, however. In this review we included grades II and III, following the WHO definition of high-grade chondrosarcomas. In addition, different definitions of late relapse ( $>1.5$ years here versus $>5$ years in the literature) might also contribute to the observed discrepancy. In this review, we found no statistically significant differences $(p=0.98)$ between OS rates of patients whose relapse had been discovered by imaging before symptoms occurred and patients whose relapse was discovered afterwards. Our small sample size does not allow us to draw any conclusions, but this question deserves further study ${ }^{[1,9]}$.

Survivorship issues have only begun to be appreciated in recent years. We did our best to evaluate them in our patient series but, frequently, we could obtain only imprecise or incomplete data. When we examined adverse effects at five years of follow-up, we mainly noted problems of fertility, functional disorders (e.g., walking, pain, and osteoporosis) and hypercholesterolemia. It is also important to note that there were no second cancers diagnosed in the five-year follow-up period.

Fertility is a major concern for young patients. It is addressed by cryoconservation procedures pre-chemotherapy, which did not occur frequently in the cases reviewed here. Among the cases for which cryoconservation was undertaken, none has been used at the time of this review. However, 5 to 13 years of follow-up might not be sufficient to interpret this result, since many of the patients are still young. Moreover, fear of relapse and a more difficult reconstruction of social relationships might present psychological obstacles to reproduction.

Metabolic syndrome is another adverse effect of chemotherapy that has been increasingly studied in recent years, but remains somewhat unexplained. This syndrome's complexity, whether in terms of etiology or definition, makes it hard to interpret our results in this regard. Moreover, there was a lack of systematic capture of relevant data in the patient files, such as weight, height, blood sugar, triglycerides, and cholesterol level. The long-term impact of metabolic syndrome on the survivors' quality of life should not be underestimated. Guidelines should be designed to ensure better monitoring and management of this side effect.

At the beginning of this review project, we also wished to investigate the psychosocial status of patients in remission. However, the retrospective nature of our study did not allow us to pursue this objective. This aspect should also be developed in follow-up guidelines, which is not currently the case, despite pressure from survivors' associations and their growing implication in research projects ${ }^{[22,23]}$.

The main weakness of this study is its retrospective nature. Missing data and patients lost to follow- up decrease the power of several of our analyses. Despite these shortcomings, our results are consistent with the ones found in the medical literature and point to the need for more comprehensive collection of survivorship data in the context of cancer treatment follow-up.

Acknowledgements: The authors wish to thank Cyril Closset and Carolyn Straehle for translation assistance and Dr Felipe Ades for the literature search.

Funding sources: None 


\section{References}

1. Hogendoorn, P.C.W., Athanasou, N., Bielack, S., et al. Bone sarcomas: ESMO Clinical Practice Guidelines for diagnosis, treatment and follow-up. (2010) Ann Oncol 21(Suppl 5): v204213.

Pubmed |Crossref $\mid$ Others

2. Burningham, Z., Hashibe, M., Spector, L., et al. The Epidemiology of Sarcoma. (2012) Clin Sarcoma Res 2(1): 14.

Pubmed | Crossref | Others

3. Jo, V.Y., Fletcher, C.D.M. WHO classification of soft tissue tumours: an update based on the 2013 (4th) edition. (2014) Pathology (Phila) 46(2): 95-104.

Pubmed | Crossref | Others

4. Stiller, C.A., Trama A, Serraino D., et al. Descriptive epidemiology of sarcomas in Europe: Report from the RARECARE project. (2013) Eur J Cancer 49(3): 684-695.

Pubmed | Crossref | Others

5. Ozaki, T., Hillmann, A., Lindner, N., et al. Metastasis of chondrosarcoma. (1996) J Cancer Res Clin Oncol 122(10): 625-628. Pubmed | Crossref $\mid$ Others

6. Khoury, J.F., Ben-Arush, M.W., Weintraub, M., et al. Alkaline phosphatase level changes in patients with osteosarcoma: its role as a predictive factor of tumor necrosis and clinical outcome. (2014) Isr Med Assoc J 16(1): 26-32.

Pubmed | Crossref $\mid$ Others

7. Bramer, J.A.M., van Linge, J.H., Grimer, R.J., et al. Prognostic factors in localized extremity osteosarcoma: a systematic review. (2009) Eur J Surg Oncol 35(10): 1030-1036.

Pubmed | Crossref | Others

8. Jawad, M.U., Haleem, A.A., Scully, S.P. Malignant sarcoma of the pelvic bones: treatment outcomes and prognostic factors vary by histopathology. (2011) Cancer 117(7): 1529-1541.

Pubmed | Crossref | Others

9. NCCN Clinical Practice Guidelines in Oncology (NCCN Guidelines $\left.{ }^{\circledR}\right)$ Bone Cancer (2013).

Pubmed | Crossref $\mid$ Others

10. Mavrogenis, A.F., Abati, C.N., Romagnoli, C., et al. Similar survival but better function for patients after limb salvage versus amputation for distal tibia osteosarcoma. (2012) Clin Orthop 470(6): 1735-1748.

Pubmed | Crossref $\mid$ Others

11. Abed, R., Grimer, R. Surgical modalities in the treatment of bone sarcoma in children. (2010) Cancer Treat Rev 36(4): 342-347.

Pubmed | Crossref $\mid$ Others

12. Longhi, A., Errani, C., De Paolis, M., et al. Primary bone osteosarcoma in the pediatric age: state of the art. (2006) Cancer Treat Rev 32(6): 423-436.

Pubmed | Crossref | Others

13. Redondo, A., Cruz, J., Lopez-Pousa, A., et al. SEOM clinical guidelines for the treatment of osteosarcoma in adults-2013. (2013) Clin Transl Oncol 15(12): 1037-1043.

Pubmed | Crossref | Others

14. Pirker-Frühauf, U.M., Friesenbichler, J., Urban, E.C., et al. Osteoporosis in children and young adults: a late effect after chemotherapy for bone sarcoma. (2012) Clin Orthop 470(10): 2874-2885.

Pubmed | Crossref | Others
15. Sánchez-Lara, K., Hernández, D., Motola, D., et al. Association between overweight, glucocorticoids and metabolic syndrome in cancer patients under chemotherapy. (2013) Nutr Hosp 28(1): 182-187.

Pubmed | Crossref | Others

16. Longhi, A., Ferrari, S., Tamburini, A., et al. Late effects of chemotherapy and radiotherapy in osteosarcoma and Ewing sarcoma patients. (2012) Cancer 118(20): 5050-5059.

Pubmed | Crossref | Others

17. Schlitt, A., Jordan, K., Vordermark D., et al. Cardiotoxicity and oncological treatments. (2014) Dtsch. Ärztebl Int 111(10): 161-168.

Pubmed | Crossref | Others

18. Janeway, K.A., Grier, H.E. Sequelae of osteosarcoma medical therapy: a review of rare acute toxicities and late effects. (2010) Lancet Oncol 11(7): 670-678.

Pubmed | Crossref | Others

19. Mason, G.E., Aung, L., Gall, S., et al. Quality of life following amputation or limb preservation in patients with lower extremity bone sarcoma. (2013) Front Oncol 3: 210.

Pubmed | Crossref | Others

20. Bacci, G., Forni, C., Longhi, A., et al. Long-term outcome for patients with non-metastatic Ewing's sarcoma treated with adjuvant and neoadjuvant chemotherapies. 402 patients treated at Rizzoli between 1972 and 1992. (2004) Eur J Cancer 40(1): 73-83.

Pubmed | Crossref $\mid$ Others

21. Li, X., Moretti, V.M., Ashana, A.O., et al. Impact of close surgical margin on local recurrence and survival in osteosarcoma. (2012) Int Orthop 36(1): 131-137.

Pubmed | Crossref | Others

22. Mols, F., Thong, M.S.Y., Vissers, P., et al. Socio-economic implications of cancer survivorship: Results from the PROFILES registry. (2012) Eur J Cancer 48(13): 2037-2042.

Pubmed |Crossref | Others

23. Survivor Stories - National Coalition for Cancer Survivorship (NCCS).

Pubmed $\mid$ Crossref $\mid$ Others

Submit your manuscript to Ommega Publishers and we will help you at every step:

- We accept pre-submission inquiries

- Our selector tool helps you to find the most relevant journal

- We provide round the clock customer support

- Convenient online submission

- Thorough peer review

- Inclusion in all major indexing services

- Maximum visibility for your research

Submit your manuscript at

https://www.ommegaonline.org/submit-manuscript 